\title{
Prevalence of Extended-Spectrum Beta-Lactamases Production in Escherichia coli Isolated from Urinary Tract Infection Samples in Zanjan Hospitals, Iran
}

\author{
Amir Pournajafi*, Arash Mahmoudi \\ Department of Biology, Central Tehran Branch, Islamic Azad University, Tehran, Iran \\ *Corresponding Author \\ Amir Pournajafi
}

\section{Article History}

Received: 26.02 .2020

Accepted: 05.03.2020

Published: 08.03.2020

\begin{abstract}
Background and Aim: The spread of ESBL in Escherichia coli isolates has led to increased antibiotic resistance and mortality. Therefore, the present study was performed to investigate the susceptibility and antibiotic resistance patterns of ESBL-producing E. coli strains isolated from patients referred to Zanjan hospitals. Materials and Methods: In this descriptive-analytical study, 260 urinary tract infection specimens were identified in Zanjan hospitals in 2019, 100 E. coli isolates were identified by standard bacteriological methods. Antibiotic susceptibility of the isolates was determined by disk diffusion method and ESBL-producing isolates were identified by combined disk method. Results: The most resistant to ampicillin (72\%) and tetracycline (50\%) were the most sensitive to amikacin (94\%) and nitrofurantoin (90\%), respectively. A total of 41 samples were identified as the final ESBL producer. Conclusion: The results indicate a relatively high prevalence of ESBL in E. coli isolates in Zanjan. Given the high prevalence rate, it is necessary to monitor the resistance pattern of gram negative isolates in Zanjan. Given the high percentage of resistance to E. coli isolates to antibiotics and to reduce the spread of resistance genes, sensitivity testing is recommended to select more effective antibiotics even for outpatient isolates.
\end{abstract}

Keywords: Extended-Spectrum Beta-Lactamases, Escherichia coli, Urinary Tract Infection, Antibiotic Resistance.

\section{INTRODUCTION}

Since sulfanamides and penicillins have come into the field, a new opportunity has emerged in the treatment of diseases. In the early days of the use of these drugs, numerous epidemics subsided. However, infections caused by infectious organisms remain a serious problem [1]. There are two important mechanisms through which increased resistance to antibiotics and other drugs. The former is due to spontaneous mutation, in the sense that the mutation occurs at a frequency of about 10 to 5\%, altering the susceptibility to the drug, and the drug acts only as a selective agent and promotes the survival of resistant organisms among organisms [2]. The second mechanism of genetic exchange resistance is the genetic information that controls the drug resistance of the bacterium to both chromosomal DNA and extra-chromosomal DNA, ie plasmids, through the transformation, conjugation, and transduction of a (resistant) cell. Transferred to another (sensitive) cell. Hospitalized patients are exposed to nosocomial infections, especially with multidrug-resistant organisms, and are one of the most important contributors to nosocomial infections and as a result mortality from Gram-negative bacilli infection. Since antibiotics, especially in ICU wards, are usually empirically due to the rush of treatment $[3,4]$ ESBLs, with the power to hydrolyze the wide range of beta-lactam antibiotics used in clinics, pose a serious problem in medicine. Bacteria producing ESBLs with class $C$ cephalosporinases encoded by the AmpC chromosomal gene have been the most common mechanism of resistance to Gram-negative bacilli against this antibiotic $[5,6]$. Since the second half of the 1980s, with the reporting of variants of ESBLs and the wide geographical distribution of these enzymes, their release has been discussed as an epidemiological phenomenon [7,8]. Urinary tract infections are one of the most common human-acquired infections. In the United States, urinary tract infections are the second most common cause of upper respiratory tract infections, and many men and women are infected throughout their lives. Different factors such as age, sex and immune system influence the prevalence of UTI [9-12]. E. coli is one of the most

Copyright @ 2020: This is an open-access article distributed under the terms of the Creative Commons Attribution license which permits unrestricted use, distribution, and reproduction in any medium for non commercial use (NonCommercial, or CC-BY-NC) provided the original author and source are credited. 
common bacterial agents isolated from human infections. The drug resistance of this bacterium is of great importance especially in hospitalized patients $[13,14]$. It is one of the most common microbial causes of urinary tract infections and is the cause of many nosocomial infections such as sepsis, wound infections, gastroenteritis and neonatal meningitis [15]. E. coli is one of the hospital opportunistic pathogens and has become resistant to beta-lactam antibiotics due to the acquisition of plasmids encoding extended-spectrum beta-lactamases [16, 17]. For this reason, treatment of infections caused by $E$. coli has become difficult $[18,19]$. The aim of this study was to evaluate clinical isolates of $E$. coli collected from hospitals in Zanjan in order to present a sensitivity pattern to experimental antibiotics and phenotypic study of ESBLs producing isolates.

\section{Materials AND Methods}

In this descriptive study, 260 urine samples were collected from outpatients and inpatients of Zanjan hospitals during three months from November to December of 2019 and were cultured on EMB (Merck Company, Germany). Then routine biochemical tests were performed on the colonies. Also, standard strain of E. coli 35218 ATCC was used as quality control. Combined disk test was used to evaluate ESBL producing strains. This experiment was performed using ceftazidime $(30 \mu \mathrm{g})$, cefotaxime $(30 \mu \mathrm{g})$, ceftazidime / clavulanic acid $(30 \mu \mathrm{g} / 10 \mu \mathrm{g})$ and Cefotaxime / clavulanic acid $(30 \mu \mathrm{g} / 10 \mu \mathrm{g})$. For this test, the isolates under study were suspended in physiological saline and their turbidity was adjusted to 0.5 McFarland standard. Then, cotton swabs were cultured in Muller Hinton Agar medium in three directions and after $24 \mathrm{~h}$ incubation at $37^{\circ} \mathrm{C}$, the growth zone diameter was recorded around the discs. Then, cotton swabs were cultured in Muller Hinton Agar medium in three directions and after $24 \mathrm{~h}$ incubation at $37^{\circ} \mathrm{C}$, the growth zone diameter was recorded around the discs. Increase in diameter of more than $5 \mathrm{~mm}$ in diameter growth zone around ceftazidime / clavulanic acid $(30 \mu \mathrm{g} / 10 \mu \mathrm{g})$ and cefotaxime / clavulanic acid $(30 \mu \mathrm{g} / 10 \mu \mathrm{g})$ discs compared to ceftazidime (30 $\mu \mathrm{g})$ and cefotaxime $(30 \mu \mathrm{g})$ discs) Indicates ESBL positive of sample and recorded as positive result. In this experiment $E$. coli ATCC 25922 was used as negative control and E. coli ATCC 35218 as positive control. After confirmation of the presence of Escherichia coli, the antibiogram for the samples was recommended by the Clinical and Laboratory Standards Institute. Antibiotic discs used were tetracycline $(30 \mu \mathrm{g})$, nitrofurantoin $(300 \mu \mathrm{g})$, ceftazidime $(30 \mu \mathrm{g})$, ampicillin sulbactam $(10 \mu \mathrm{g})$, amoxicillin $(25 \mu \mathrm{g})$, amoxicillin-clavulanic $(25 \mu \mathrm{g})$, nalidixic acid $(30 \mu \mathrm{g})$, amikacin $(30$ $\mu \mathrm{g})$, tobramycin $(10 \mu \mathrm{g})$, imipenem $(10 \mu \mathrm{g})$, ciprofloxacin $(5 \mu \mathrm{g})$ and gentamicin $(10 \mu \mathrm{g})$, (Media Companies). After 24hour incubation at $37^{\circ} \mathrm{C}$ using a ruler, the growth zone around the discs was measured and compared to the CLSI standards. According to the manufacturer's instructions, the results were based on sensitivity (S) and resistance (R) was reported and semi-susceptible halos were recorded as (I).

\section{RESULTS}

In this study, 260 urine samples were collected from 100 (38.46\%) E. coli. 64 specimens were isolated from the inpatients ward and 36 samples from the outpatients ward. Based on the results of the combined disk test, 41 samples were identified as final ESBL producers. The results of the sensitivity test against the 12 selected antibiotics are shown in Figure-1.

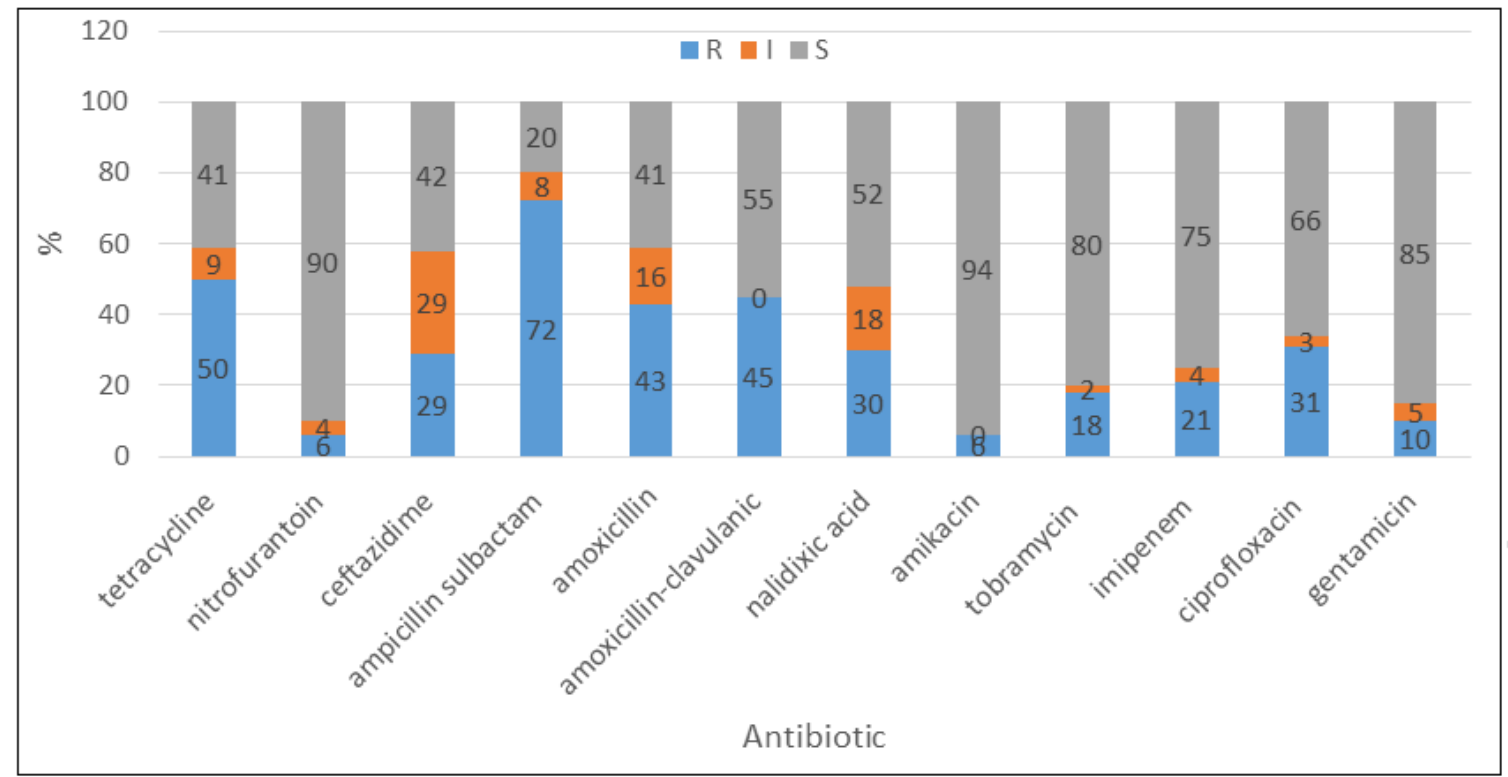

Fig-1: Frequency of antibiotic resistance pattern of $E$. coli strains isolated from urinary tract infections 


\section{DISCUSSION}

Broad-spectrum beta-lactamases are a group of beta-lactamase enzymes that are of particular importance in antimicrobial therapy. The rate of ESBL production among Enterobacteriaceae varies worldwide [20]. In the present study, from $100 \mathrm{E}$. coli isolates, 64 samples from the inpatient ward and 36 samples from the outpatients ward were isolated. Based on the results of the combined disk test, 41 samples were identified as final ESBL producers. The highest resistance to ampicillin (72\%) and tetracycline (50\%) were the most sensitive to amikacin (94\%) and nitrofurantoin $(90 \%)$, respectively. Kasmaei et al., by studying E. coli isolated from urinary tract infection, found that the samples were most resistant to ceftriaxone and nalidixic acid (100\%) [21]. Mobasherizadeh et al., found in a study of E. coli strains isolated from urinary tract infections that most strains were resistant to ampicillin. Which was consistent with the findings of the present study [22]. Feiz Sarshar and Akya showed the highest and lowest resistance to ampicillin and carbapenem antibiotics, respectively, from the 60 isolates tested in $2016.45 \%$ of the isolates were ESBL-producing enzyme [23]. Masjedian and colleagues examined 51\% of the 148 E. coli strains reported producing ESBL [24]. Mirsalehian and colleagues reported 59.3\% of the samples as ESBL producers [25]. In a study by Soltan Dallal et al., on 200 E. coli isolates, $64 \%$ of the isolates reported ESBL-producing [26, 27]. Amirmozafari and colleagues showed that 2018 out of 167 E. coli isolates, 38.9\% were ESBL positive [28]. Regional differences in different parts of the world give rise to different antibiotic responses, and even patterns of antibiotic resistance may vary from one hospital to another in one country. The origin of these differences are: genetic differences between individuals, genetic differences of strains, differences in cultural and economic backgrounds. Therefore the treatment pattern used in different regions is different depending on the specific characteristics of a region.

\section{CONCLUSION}

Due to the increased antibiotic resistance among the strains, it is recommended that antibiogram testing be performed before treatment. Also, preventing bacterial strains and therapeutic failures that lead to complication of the infection can be prevented by proper use of existing medicines, completing the course of treatment and avoiding as many antibiotics as possible. Further research in this field will increase our knowledge and more effective exposure to the antibiotic resistance of emerging microorganisms.

\section{REFERENCES}

1. Al Jasser, A. M. (2006). Extended-spectrum beta-lactamase (ESBLS): a global problem. Kuwwait Medical, 38(3):171-185.

2. Medeiros, A. A. (1997). Evolution and dissemination of $\beta$-lactamases accelerated by generations of $\beta$-lactam antibiotics. Clinical Infectious Diseases, 24(Supplement_1), S19-S45.

3. Ensor, V. M., Livermore, D. M., \& Hawkey, P. M. (2007). A novel reverse-line hybridization assay for identifying genotypes of CTX-M-type extended-spectrum $\beta$-lactamases. Journal of Antimicrobial Chemotherapy, 59(3), 387395.

4. Dizaji, A. S., Fathi, R., \& Sales, A. J. (2016). Molecular study of extended-spectrum beta-lactamase (TEM-1) gene in Escherichia Coli isolates collected from Ostad Alinasab Hospital in Tabriz Iran. MMJ, 29:35-40.

5. Jafari-Sales, A., \& Shadi-Dizaji, A. (2018). Molecular analysis of CTX-M genes among ESBL producing in Pseudomonas aeru-ginosa isolated from clinical samples by Multiplex-PCR. HOZAN J Environment Sci, 2(5), 1729.

6. Coque, T. M., Baquero, F., \& Canton, R. (2008). Increasing prevalence of ESBL-producing Enterobacteriaceae in Europe. Eurosurveillance, 13(47), 19044.

7. Rupp, M. E., \& Fey, P. D. (2003). Extended spectrum $\beta$-lactamase (ESBL)-producing Enterobacteriaceae. Drugs, 63(4), 353-365.

8. Biedenbach, D. J., Lewis, M. T., \& Gones, R. N. (1999). Invitro evaluation of cefepime and other road-spectrum pIactams for isolates in Malaysia and Singapore Antimicrobial Resistance Study group. Diagn Microbiol Infect Dis, 35, 277-83.

9. Jafari-Sales, A. (2018). Study of Antibiotic Resistance and Prevalence of bla-TEM gene in Klebsiella pneumoniae Strains isolated from Children with UTI in Tabriz Hospitals. Focus On Medical Sciences Journal, 4(1).

10. Wagenlehner, F. M., Naber, K. G., \& Weidner, W. (2008). Rational antibiotic therapy of urinary tract infections. Medizinische Monatsschrift fur Pharmazeuten, 31(10), 385-90.

11. Jafari Sales, A., \& Mobaiyen, H. (2017). Frequency and resistance patterns in clinical isolates of Escherichia coli Extended Spectrum Beta Lactamase producing treatment Centers in Marand city, Iran. New Cellular and Molecular Biotechnology Journal, 7(26), 19-26.

12. De Francesco, M. A., Ravizzola, G., Peroni, L., Negrini, R., \& Manca, N. (2007). Urinary tract infections in Brescia, Italy: etiology of uropathogens and antimicrobial resistance of common uropathogens. Medical science monitor, 13(6), BR136-BR144. 
13. Jafari-Sales, A., \& Rasi-Bonab, F. (2017). Detection of the antibiotic resistance pattern in Escherichia coli isolated from urinary tract infections in Tabriz City. J Mol Microbiol, 1(1), 1-3.

14. Jafari Sales, A., Hosein-Nezhad, P., \& Shahniani, A. (2020). Antibiotic susceptibility assessment of Escherichia coli isolated from traditional cheeses in Marand, Iran. International Journal of Advanced Biological and Biomedical Research, 8(3):236-241.

15. Jafari Sales, A., Mobaiyen, H., Farshbafi Nezhad Zoghi, J., Nezamdoost Shadbad, N., \& Purabdollah Kaleybar, V. (2014). Antimicrobial resistance pattern of extended-spectrum $\beta$-Lactamases (ESBLs) producing Escherichia coli isolated from clinical samples in Tabriz city, Iran. Adv Environ Biol, 8(16), 179-82.

16. Sales, A., Fathi, R., \& Mobaiyen, H. (2017). Molecular Study of the Prevalence of CTX-M1, CTX-M2, CTXM3 in Pseudomonas aeruginosa Isolated from Clinical Samples in Tabriz Town, Iran. Electronic J Biol, 13(3), $253-9$.

17. Khalili, M. B., MK, S. Y., Ebadi, M., \& Sadeh, M. O. J. T. A. B. A. (2007). Correlation between urine analysis and urine culture in the diagnosis of urinary tract infection in Yazd central laboratory. Tehran University Medical Journal TUMS Publications, 65(9), 53-58.

18. Jafari-Sales, A., Bagherizadeh, Y., Khalifehpour, M., Abdoli-senejan, M., \& Helali-Pargali, R. (2019). Antibiotic resistance pattern and bla-TEM gene expression in Acinetobacter baumannii isolated from clinical specimens of Tabriz hospitals. Zanko Journal of Medical Sciences, 20(65), 20-29.

19. Tarbiat-Nazloo, D., Jafari-Sales, A., Bagherizadeh, Y., Abdoli-senejani, M., Farhadi, F., \& Ezdiyadi, M. (2019). Identification of phylogenetic groups of Escherichia coli isolated from colibacillosis in poultry by multiplex-PCR. New Findings in Veterinary Microbiology, 1(2): 89-94.

20. Falagas, M. E., \& Karageorgopoulos, D. E. (2009). Extended-spectrum $\beta$-lactamase-producing organisms. Journal of Hospital infection, 73(4), 345-354.

21. Kasmaei, Z., Nouri, A. M., Tehrani, H. F., \& Arashkia, A. (2012). Determination of drug sensitivity in Escherichia coli with multiple drug resistance in outpatients with urinary tract infections in Tehran. Iranian J Microbiol, 6(3), 37-44.

22. Mobasherizadeh, M., Bidoki, S. K., \& Mobasherizadeh, S. (2016). Prevalence of CTX-M genes in Escherichia coli strains in outpatient and inpatient cases with urinary tract infections in Isfahan, Iran. Journal of Isfahan Medical School, 33(360), 2020-2025.

23. Sarshar, M. H. F., \& Akya, A. (2016). The frequency of extended spectrum $\beta$-lactamase genes of SHV-2a, SHV-5 and SHV-12 in clinical isolates of klebsiella pneumoniae isolated from Kermanshah medical centers in 2014. Majallah-i dānishgāh-i úūm-i pizishkī-i Arāk, 19(2), 59-67.

24. Masjedian, G. F., Valehi, F., Talebi, R. L. A., \& Rastegar, L. (2007). Moulecular evaluation of resistance to espanded antibiotics in Escherichia coli and Klebsiella pneumoniae. Iran J Med Microbiol, 1(2), 27-34.

25. Mirsalehian, A., AKBARI, N. F., Peymani, A., Kazemi, B., JABAL, A. F., \& Mirafshar, S. M. (2008). Prevalence of extended spectrum $\beta$-lactamase-producing Enterobacteriaceae by phenotypic and genotypic methods in intensive care units in Tehran, Iran. Daru, 16(3):169-173.

26. Dallal, M. M. S., Sabbaghi, A. Y. L. A. R., Fallah, J. A. L. I. L., Aghamirzaei, H. M., Lari, A. R., Eshraghian, M. R., \& Sanei, A. F. (2010). Evaluation of presence of the bla-SHV and bla-AmpC (CITM, FOX) $\beta$-lactamase genes in clinical isolates of Escherichia coli. Journal of Medical Council of Islamic Republic of Iran, 28(3).

27. Soltan Dallal, M. M., Aghamirzaei, H. M., Mehrabadi, J. F., Lari, A. R., Sabbaghi, A., Eshraghian, M. R., ... \& Abdar, M. H. (2010). Molecular detection of TEM and AmpC (Dha, mox) broad spectrum $\beta$-lactamase in clinical isolates of Escherichia coli. Tehran University Medical Journal, 68(6).

28. Amirmozafari, N., BabaieKasmaie, Z., \& Mohsenpour, M. (2018). The Frequency of Beta Lactamase genes in Escherichia coli isolates from outpatient suffering from urinary tract infections in Guilan province. Yafteh, 19(5), 43-52. 